\title{
Dimethylaminomicheliolide (DMAMCL) Inhibits Cell Proliferation and Increases Apoptosis and Efficacy of Gemcitabine via Annexin A2 in Pancreatic Adenocarcinoma
}

Kaihui Liu

Nankai University

Jianshuang Guo

Nankai University

Ning Liu

Nankai University

Jiyan Wang

Nankai University

Mukuo Wang

Nankai University

Yanwei Zhang

Nankai University

Hao Jiang

Nankai University

Yanling Liu

Dezhou University

Fangzhong Hu

Nankai University

Wenzheng Fu

PLA Strategic Support Force Medical Center

Chunze Zhang

PLA Strategic Support Force Medical Center

Lianyong Li

Tianjin Union Medical Center

Mengyi Zhang

Nankai University

Jing Li ( $\nabla_{\text {jinglink@nankai.edu.cn ) }}$

Nankai University 


\section{Research Article}

Keywords: Dimethylaminomicheliolide, Pancreatic adenocarcinoma, Annexin A2, Gemcitabine, Proliferation, Apoptosis

Posted Date: August 9th, 2021

DOl: https://doi.org/10.21203/rs.3.rs-737712/v1

License: (c) (i) This work is licensed under a Creative Commons Attribution 4.0 International License.

Read Full License 


\section{Abstract}

Background: Pancreatic adenocarcinoma is one of the highest malignant tumors in digestive tract with extremely poor survival rate. Dimethylaminomicheliolide (DMAMCL) is a clinical developing anti-cancer agent, however, little is known regarding its effects in pancreatic cancer, and the mechanisms of DMAMCL are still not fully understood.

Methods: This study evaluated DMAMCL on three pancreatic cancer cell lines by cell viability assay, colony formation assay, and apoptosis assay. To identify the direct binding target of DMAMCL in pancreatic cells, a chemical proteomics approach, molecular docking and site-directed mutagenesis were performed.

Results: DMAMCL inhibits proliferation and promotes apoptosis of pancreatic cancer cells. Interestingly, using a chemical proteomics approach, we identify ANXA2 as a direct binding target of DMAMCL in pancreatic cells. Molecular docking and site-directed mutagenesis confirm that Cys132 (C132) of ANXA2 is the binding site for DMAMCL. The knockdown of ANXA2 largely decreases the inhibition activity of DMAMCL, indicating that the effect of DMAMCL is mainly mediated by ANXA2 in pancreatic cancer. In addition, the combination regimen of gemcitabine and DMAMCL exhibits synergistic effect on pancreatic cancer cell lines at both proliferation and pro-apoptosis level.

Conclusions: Thus, our findings elucidate the mechanisms of DMAMCL and may provide a potential strategy to enhancing the efficacy of gemcitabine in pancreatic adenocarcinoma.

\section{Background}

Pancreatic adenocarcinoma is the fourth leading cause of cancer-related deaths in the world [1]. Nowadays, gemcitabine has become the first-line therapy as single injection or combination with surgery and radiation [2-4]. However, due to the high degree of intrinsic or acquired resistance, the efficacy of gemcitabine still needs improved, with a response rate of about 5\% [5]. Therefore, systematic chemotherapy with novel anti-cancer agents or molecular targeting agents is necessary [6].

Annexin A2 (ANXA2) is part of the Annexin family that bind anionic phospholipids in a calciumdependent manner [7]. It is up-regulated in various cancer types (nasopharyngeal carcinoma, ovarian cancer, gliomas, hepatomas, pancreatic cancer, and breast cancer) and promotes cancer progression including proliferation, invasion, and metastasis [8-13]. In 1993, Vishwanatha et al. measured the levels of ANXA2 mRNA and protein in normal human pancreas, five pancreatic adenocarcinoma cell lines, three primary pancreatic tumors and one metastatic pancreatic tumor [14]. All pancreatic cancer cell lines examined had 5 - to 15 -fold higher levels of ANXA2 as compared to normal pancreas. Significant elevations (2- to 8-fold) of ANXA2 expression were observed in the primary and metastatic pancreatic tumors. Further immunocytochemical analysis indicated that the increased expression of ANXA2 was colocalized with cells that express proliferating cell nuclear antigen (PCNA), indicating the role of ANXA2 in cell proliferation of pancreatic cancer [15]. Using two-dimensional gel electrophoresis, Takano et al. 
discovered that ANXA2 was a gemcitabine-resistant factor by comparing the protein profiling of gemcitabine-resistant (GEM-) and wild type (WT-) MIA PaCa-2 cell lines. In addition, immunohistochemistry of pancreatic cancer tissues demonstrated that the overexpression of ANXA2 was significantly associated with rapid recurrence after gemcitabine adjuvant chemotherapy [16]. Therefore, ANXA2 could be a potential drug target for enhancing the sensitivity of gemcitabine in pancreatic cancer treatment.

DMAMCL is a novel anti-cancer agent and has been under clinical trials in Australia for treatment of glioma tumors (trial number: ACTRN12616000228482). It suppresses glioma by regulating $\mathrm{PI} 3 \mathrm{~K} / \mathrm{AKT} / \mathrm{mTOR}$ signaling pathway, NF $k \mathrm{~B}$ signaling pathway, ROS, and rewiring aerobic glycolysis [1720]. In addition, DMAMCL can also inhibit leukemia cell and liver cancer cell growth [21,22]. However, the potential effect of DMAMCL on pancreatic cancer and related mechanism has not yet reported.

In this study, we employed cell viability assay, colony formation assay, and apoptosis assay to demonstrate the effect of DMAMCL on cell viability and apoptosis in three pancreatic cancer cell lines (PANC-1, AsPC-1, BxPC-3). Chemo-proteomics, amino acid mutation, molecular modeling, and gene knock-down by RNAi were performed to verify that DMAMCL suppressed pancreatic cancer cells by targeting Cys132 (C132) of ANXA2. Moreover, we evaluate the synergistic effect between DMAMCL and gemcitabine on three pancreatic cancer cell lines. Overall, our results reveal that DMAMCL inhibits cell proliferation, promotes cell apoptosis, and increases the sensitivity of gemcitabine in pancreatic adenocarcinoma, which provides a novel strategy for the treatment of pancreatic cancer.

\section{Methods}

\section{Chemicals}

DMAMCL and its active metabolic form micheliolide (MCL) were synthesized as previously reported [23]. The positive probe (MCL-biotin) and the negative probe (MCL-S-biotin, NP) were synthesized as described [21]. Gemcitabine was obtained from Med Chem. Express (CAS: 95058-81-4).

\section{Cell culture}

Human pancreatic cancer cell lines (PANC-1, AsPC-1, BxPC-3) were originally obtained from JIKAI GENE (NICR, 3111C0001CCC000023, 3111C0001CCC000214, 3142C0001000001478). PANC-1 cells were cultured in DMEM medium (Corning, 10-017-CVR) supplemented with $10 \%$ fetal bovine serum (BI, $04010-$ $1 \mathrm{~A}$ ) and penicillin/streptomycin (Sigma, V900929) in a humidified incubator with $5 \% \mathrm{CO}_{2}$ at $37^{\circ} \mathrm{C}$. AsPC1 cells and BxPC- 3 cells were cultured in RPMI1640 medium (Corning, 10-040-CVR) supplemented with $10 \% \mathrm{FBS}$ in a humidified incubator with $5 \% \mathrm{CO}_{2}$ at $37^{\circ} \mathrm{C}$.

\section{Cell viability assay}


For cell viability assay, human pancreatic cancer cell lines were seeded in 96-well-plates (4000 cells/well). Cells were treated with varying concentrations of DMAMCL or MCL for a certain time. After 48 or $72 \mathrm{~h}, 20$ $\mu \mathrm{L}$ MTT reagent (Solarbio, M8180) $(5 \mathrm{mg} / \mathrm{mL})$ was added to each well. After 4-h incubation, the liquid in the wells was replaced by $150 \mu \mathrm{L}$ dimethyl sulfoxide (DMSO). Cell viability was determined by optical density (OD) values at $570 \mathrm{~nm}$.

\section{Colony formation assay}

For colony formation assay, human pancreatic cancer cell lines were seeded in 6-well-plate (2000 cells/well). Cells were treated with varying concentrations of DMAMCL or MCL for 14 days. After that, the culture medium was discarded, and cells were fixed with ice methanol for $15 \mathrm{~min}$. Fixed cells were stained with crystal violet (Solarbio, G1063) for 15 min and washed 3 times with PBS. Finally, the plates were photographed by a digital camera.

\section{Apoptosis assay}

The apoptosis assay was detected by FITC coupled with Annexin-V apoptosis detection kit (Beyotime, C1062). PANC-1 cells were seeded in 6-well-plates $\left(2 \times 10^{5}\right.$ cells/well). After cells adhered overnight, they were treated with different concentrations of DMAMCL or MCL, with or without gemcitabine. After $48 \mathrm{~h}$ treatment, cells were washed 3 times with PBS and digested with trypsin without EDTA (Gibco) in EP tubes, followed by centrifugation at $1000 \mathrm{~g}$ for $3 \mathrm{~min}$. The cell pellets were washed twice with PBS, following by adding $100 \mu \mathrm{L} 1 \times$ binding buffer to suspend the cells. For cell staining, $5 \mu \mathrm{L}$ FITC Annexin $V$ and $5 \mu \mathrm{L}$ of PI were added to each tube and incubated at room temperature (keep in dark) for $15 \mathrm{~min}$. Finally, each tube was supplemented with $400 \mu \mathrm{L} 1 \times$ binding buffer. The samples were analyzed by FACSCalibur flow cytometer (Beckman, BD LSRFortessa ), and the data was analyzed by FlowJo 7.6.1 software $(10,0,0,0)$.

\section{Chemo-proteomics to identify MCL-bound proteins}

Pull-down experiment was carried out according to the method of literature [24]. Briefly, BxPC-3 cells were plated on $10 \mathrm{~cm}^{2}$ cell culture dish and grown to confluence for $24 \mathrm{~h}$. Cells were harvested and lysed in NP40 lysed buffer containing 1 mM PMSF and protease inhibitors. MCL-biotin (Probe) or MCL-S-biotin (NC probe) was incubated with cell lysates overnight at $4^{\circ} \mathrm{C}$, then the prewashed streptavidin beads (Thermo, 20349) were added to each sample and incubated overnight at $4^{\circ} \mathrm{C}$. On the second day, the beads ware washed six times with lysis buffer, and the bead-bound proteins were eluted and boiled in 2×SDS loading buffer. The bead-bound proteins were separated by SDS-PAGE and visualized by silver staining. The protein-containing band in the gel was excised, followed by in-gel digestion and analysis by LC-MS/MS. 


\section{Site-directed mutant assay}

Site-directed mutant assay was constructed using QuikChange II XL site-directed mutagenesis kit (Stratagene, USA). In order to mutate the cysteine at position 132 of pETM3C-ANXA2 plasmid to glycine, primers were designed (forward, 5'-CTCATTGAGATCATCGGCTCCAGAAC-3'; reverse, 5'-

CTCCTGAGAGAGTAA CTCTAGTAGC-3') and synthesized (GENEWIZ, China). According to the instructions of the site-directed mutagenesis kit, the mutated plasmid was obtained by PCR. Agarose gel electrophoresis was used to detect whether the target band of the PCR product is correct. If the target band was correct, added $1 \mu \mathrm{L}$ of DMT enzyme to the PCR product and mixed well. The mixture was kept in a $37^{\circ} \mathrm{C}$ water bath for $1 \mathrm{~h}$ to obtain digestion products. The digested product was purified by agarose gel DNA recovery kit (TIANGEN, DP209-03). The purified PCR product was transformed to E.coli strain $\mathrm{DH} 5 \mathrm{a}$, and the plasmid was extracted according to the plasmid extraction instructions, and then sent to the company for sequencing. The finally confirmed target plasmid was transformed into E. colistrain BL21 (DE3) for the expression and purification of protein.

\section{Molecular docking}

The molecular docking experiment was performed with Schrodinger software. The ANXA2 protein structure was downloaded from the UniProt datebase (https://www.uniprot.org), and the protein was optimized through Schrodinger software to obtain the best protein model. The three-dimensional structure of MCL was prepared using Chemdraw software. LigPrep tool was used to minimize the energy of the ligand to correct the coordinates, ionization, stereochemistry, and tautomeric substitution structure to obtain the proper conformation by adding or removing hydrogen bonds. Gliding agent ligand docking was used to dock MCL to the active site of ANXA2, and calculate the binding energy. All docking calculations used Glide XP (super precision) mode.

\section{Expression and purification of recombinant ANXA2}

The pETM3C-ANXA2 plasmid was transformed into BL21 competent cells, coated on a kana-resistant solid medium plate, and placed in a $37^{\circ} \mathrm{C}$ incubator for $12-14 \mathrm{~h}$. Monoclonal strains were picked into 5 $\mathrm{mL}$ of LB medium with kana resistance and shaken overnight at $37^{\circ} \mathrm{C}$ and $180 \mathrm{rpm}$ constant temperature shaker. The bacterial liquid obtained above was transferred to $250 \mathrm{~mL}$ of LB medium with kana resistance, and expanded for $4 \mathrm{~h}$ at $37^{\circ} \mathrm{C}$ and $180 \mathrm{rpm}$ constant temperature shaker. The bacterial solution was added to $25 \mu \mathrm{L} \mathrm{IPTG}(1 \mathrm{mmol} / \mathrm{L})$, and it was induced for $20 \mathrm{~h}$ at $18^{\circ} \mathrm{C}$ and $180 \mathrm{rpm}$ constant temperature oscillator. The bacterial solution was collected, centrifuged at $4000 \mathrm{rpm}, 4^{\circ} \mathrm{C}$ for $30 \mathrm{~min}$, and the supernatant was discarded. The pellet was resuspended in an appropriate volume of $1 \times$ bacteriolytic buffer and stored at $-80^{\circ} \mathrm{C}$ for the next step of purification. The bacterial pellet was ultrasonically disrupted for $15 \mathrm{~min}$, centrifuged at $4000 \mathrm{rpm}, 4^{\circ} \mathrm{C}$ for $30 \mathrm{~min}$, and the supernatant was collected. The supernatant was added to a nickel column equilibrated with $10 \mathrm{mM}$ imidazole in advance, and repeated 2 
times. Contaminated proteins were eluted with $30 \mathrm{mM}$ imidazole until the collection solution detected by Coomassie Brilliant Blue $\mathrm{G} 250$ was not blue. The target protein was eluted with $250 \mathrm{mM}$ imidazole and collected into $1.5 \mathrm{~mL}$ centrifuge tubes on ice until the collection solution detected by Coomassie Brilliant Blue $\mathrm{G} 250$ was not blue. $20 \mu \mathrm{L}$ of eluate were drawn from each tube, and $5 \mu \mathrm{L}$ of $5 \times$ loading buffer was added to the suction fluid, mixed, and boiled to obtain protein samples. The protein purity was detected by SDS-PAGE and Coomassie Brilliant Blue G250 copying method. The high-purity protein collection solution was used to remove imidazole by ultrafiltration, and then the protein solution was obtained by adding an appropriate volume of physiological saline.

The same procedure was used to express and purify the pETM3C-ANXA2-C132G mutant.

\section{Lentiviral transduction}

293T cells were seeded in a 6-well plate $\left(3.5 \times 10^{5}\right.$ cells/well) and cultured overnight in a humidified incubator with $5 \% \mathrm{CO}_{2}$ at $37^{\circ} \mathrm{C}$. The medium was changed to serum-free medium ( $1 \mathrm{~mL} /$ well) before cell transfection. According to the instructions of JIKAI GENE, the lentiviral packaging systems corresponding to the three plasmids of ANXA2-RNAi (16427-1), ANXA2-RNAi (16423-1) and ANXA2-RNAi (16424-1) plasmids were obtained, and the system volume of each is $50 \mu \mathrm{L}$. The lentivirus packaging system was added to 293T cells and incubated in a humidified incubator with $5 \% \mathrm{CO}_{2}$ at $37^{\circ} \mathrm{C}$ for $6 \mathrm{~h}$. After $6 \mathrm{~h}$, the mediums in the cells were replaced with new complete mediums $(2 \mathrm{~mL} /$ well). After the cells were cultured in a humidified incubator with $5 \% \mathrm{CO}_{2}$ at $37^{\circ} \mathrm{C}$ for $48 \mathrm{~h}$ or $72 \mathrm{~h}$, shRNA virus was obtained, and the shRNA virus was centrifuged to take the supernatant for use or stored at $-80^{\circ} \mathrm{C}$. For lentiviral transduction, AsPC1 cells were cultured in serum-free medium containing lentivirus for $6 \mathrm{~h}$, then replaced by new complete medium for $24 \mathrm{~h}$. For generating stable cell lines, infected cells were selected with $1 \mu \mathrm{g} / \mathrm{mL}$ puromycin (Sigma, 540411) for $72 \mathrm{~h}$. Western blot experiments verified which plasmid has the best knockdown effect and used it for the next knockdown experiment.

\section{Western blot analysis}

Cell lines were lysed in NP40 lysis buffer with protease inhibitors and the total protein concentration was quantified by BCA assay (Thermo Fisher Scientific, 23227). The normalized samples were analyzed by SDS-PAGE and western blot using standard protocols and the following primary antibodies: anti-ANXA2 (1:2000 dilution, Immunoway, YT0236), anti-AKT (1:2000 dilution, Cell Signaling, 9272S), anti-pAKT (S473) (1:1000 dilution, Cell Signaling, 4060S), anti-a-tublin (1:5000 dilution, TEL, KM9007), anti-GAPDH (1:5000 dilution, Cell Signaling, 2118S), goat anti-rabbit HRP-IgG (1:5000 dilution, Solarbio, SE134), goat anti-mouse HRP-IgG (1:5000 dilution, Solarbio, SE131).

\section{Synergy index calculation}


Human pancreatic cancer cell lines were seeded in 96-well plates (4000 cells/well). The cells were treated with DMAMCL, gemcitabine and DMAMCL combined gemcitabine (concentration ratio 1:3) for $72 \mathrm{~h}$, respectively. After 72 h, $20 \mu \mathrm{L}$ MTT reagent (Solarbio, M8180) $(5 \mathrm{mg} / \mathrm{mL})$ was added to each well. After 4 $\mathrm{h}$ incubation, the liquid in the wells was replaced by $150 \mu \mathrm{L}$ dimethyl sulfoxide (DMSO). Cell viability was determined by optical density (OD) values at $570 \mathrm{~nm}$ and the inhibition rate of each treatment was calculated. The inhibition effect and drug combination index of DMAMCL and gemcitabine was calculated by the Compusyn software (Dr. Dorothy Chou) using constant drug concentration ratio.

\section{Statistical analysis}

Results are representative examples of three individual experiments. Statistical analysis and graphical presentation were using GraphPad Prism 5.0. $P$ values were determined by a two-tailed Student's $t$ test. All histogram data was presented as mean \pm SEM. ${ }^{*}, \mathrm{P}<0.05$ and $* *, \mathrm{P}<0.01$.

\section{Results}

\section{DMAMCL inhibits proliferation and promotes apoptosis of pancreatic cancer cells}

To investigate the effect of DMAMCL on the proliferation of pancreatic cancer cells, we performed cell viability assays on AsPC-1, BxPC-3 and PANC-1 cells (Table 1). Cells were treated with different concentrations of DMAMCL or its active metabolite MCL for $72 \mathrm{~h}$, and then performed MTT assay. The results show that $\mathrm{IC}_{50}$ values of DMAMCL in AsPC-1, BxPC-3 and PANC-1 were $37.76 \pm 1.58 \mu \mathrm{M}, 35.83 \pm$ $1.55 \mu \mathrm{M}$, and $19.66 \pm 1.29 \mu \mathrm{M}$, respectively, and the $\mathrm{IC}_{50}$ values of MCL in AsPC-1, BxPC-3 and PANC-1 were $18.79 \pm 1.27 \mu \mathrm{M}, 11.73 \pm 1.07 \mu \mathrm{M}$, and $6.08 \pm 0.78 \mu \mathrm{M}$, respectively. Compared to AsPC-1 and BxPC3, PANC-1 behaves more sensitive to DMAMCL and MCL. Furthermore, we investigated the effect of DMAMCL on the anchorage-independent growth of pancreatic cancer cells through colony formation assays. It was observed that the inhibition of DMAMCL on the foci formation of AsPC-1 and PANC-1 was enhanced in a dose-dependent manner, and MCL also has a similar effect (Figure 1A). These results indicated that DMAMCL could inhibit the proliferation of pancreatic cancer cells.

In order to explore the effect of DMAMCL on the apoptosis of pancreatic cancer cells, cell apoptosis was detected by flow cytometry analysis and further confirmed by western blot. PANC-1 cells were treated with different concentrations of DMAMCL or MCL for $48 \mathrm{~h}$. PI-Annexin $\mathrm{V}$ analysis (Figure 1B) showed that DMAMCL and MCL promoted PANC-1 cell apoptosis in a dose-dependent manner. Compared to DMSO treatment group, both $20 \mu \mathrm{M}$ DMAMCL and $10 \mu \mathrm{M}$ MCL improved $20.4 \%$ and $45.4 \%$ apoptosis respectively. Western blotting (Figure 1C) showed that DMAMCL treatment promoted the activation of caspase- 9 and the release of cytochrome $\mathrm{C}$ in PANC- 1 cells, which is consistent with the study of DMAMCL-induced apoptosis in hepatocellular carcinoma by Shunnan Yao et al[25]. The above results 
indicate that DMAMCL may promote apoptosis of pancreatic cancer cells in a caspase-dependent manner.

\section{MCL directly binds to Cys132 of ANXA2 in BxPC-3 cell}

To identify the cellular targets of DMAMCL, we performed chemical proteomics assay in BxPC-3 cell. The main active metabolite of DMAMCL is MCL, which contains a typical a-methylene-y-lactone group that can react with -SH of cysteine in accessible proteins, and induce a covalent modification [26]. Thus, using biotin-conjugated MCL (MCL-biotin, Probe) and biotin-conjugated inactive MCL (MCL-S-biotin, NC probe) as probes (Figure 2A), we explored the targets of DMAMCL in BxPC-3 cells. Cellular lysates were firstly incubated with Probe or NC probe, and the mixture was pulled down with streptavidin-coated agarose beads. Then precipitated proteins on beads were resolved by SDS-PAGE and detected by silver staining. Special proteins bands in Probe treatment was excised and confirmed by LC-MS/MS. Peptide mass fingerprinting data analysis revealed that 13 peptides of ANXA2 were detected in the mass spectrometry, which confirmed ANXA2 was one target of MCL. Immunoblotting was further used to monitor the presence of ANXA2 in the precipitates. The results showed that a single band with a molecular weight of about 38 kDa was clearly precipitated with Probe instead of NC probe, indicating ANXA2 was present in the precipitate (Figure 2B). Furthermore, the amount of ANXA2 in precipitate increased with the probe in concentration-dependent manner (Figure 2C). Using 20-fold excess MCL as a competitor, ANXA2 was disappeared in pull down precipitate of Probe (Figure 2D), which further suggested that MCL directly binds to ANXA2.

ANXA2 is highly expressed in pancreatic cancer cells and has four cysteine residues (Cys-8, Cys-132, Cys261, and Cys-334) [7]. To further explore the site of MCL binding to ANXA2, molecular docking experiments and site-directed mutation experiments were performed. Molecular docking predicted that Cys132 (C132) of ANXA2 could be the binding residue for MCL with the lowest binding free energy as -3.084 (Figure 2E). Then we constructed plasmid containing C132G mutation of ANXA2 and expressed it in E. coli. Probe incubation and western blot assay showed that recombinant ANXA2 with C132G mutation displayed less binding signal with Probe (Figure 2F), which confirmed Cys132 was the main binding site of MCL.

\section{ANXA2 is upregulated in cancer patients and affects the inhibition activity of DMAMCL in pancreatic cancer cells}

ANXA2 is a member of vertebrate annexins. To clarify its role in cancer, the expression of ANXA2 in different types of cancer patients was examined through the HPA database (https://www.proteinatlas.org). Among seventeen types of cancer examined, patients with pancreatic cancer has the highest expression of ANXA2 (Figure 3A). When compared the expression levels of ANXA2 between three primary tumors (glioma, colorectal cancer, pancreatic cancer) and corresponding normal 
tissues, ANXA2 were up-regulated in all three examined tumors (Figure 3B). By correlating ANXA2 with overall survival in cancer patients, we founded that high levels of ANXA2 was associated with a low survival probability, whereas low ANXA2 expression predicted a relatively high survival probability (Figure 3C). These results indicated that ANXA2 could be a potential marker and drug target for cancer treatment.

In order to verify whether DMAMCL or MCL inhibited pancreatic cancer proliferation by targeting ANXA2, we performed dose inhibition assays on AsPC-1-WT and AsPC-1-sh ANXA2 cells (Figure 3D). After treatment with MCL for $48 \mathrm{~h}$, AsPC-1-shANXA2 cells showed less sensitivity to MCL, indicating that knockdown of ANXA2 partially abrogate the inhibition effect of MCL in AsPC-1 cells. Thus, ANXA2 was considered as one of the crucial drug targets for DMAMCL in pancreatic cancer cells.

\section{DMAMCL enhances the inhibition effects of gemcitabine in pancreatic cancer cells}

Gemcitabine is one of the first-line chemotherapeutic agent for pancreatic cancer and its low clinical response is related to the high expression of ANXA2 $[14,16,27]$. Considering DMAMCL binds to ANXA2, we performed cell viability assays of gemcitabine with or without DMAMCL on three pancreatic cancer cells. The cells were treated with different concentrations of DMAMCL, gemcitabine or DMAMCL+ gemcitabine (mixed in proportion) for $72 \mathrm{~h}$ and then for MTT assay. Compared with DMAMCL or gemcitabine alone, DMAMCL combined gemcitabine significantly inhibited the proliferation of pancreatic cells (Figure 4A). In order to verify whether DMAMCL and gemcitabine produce a synergistic effect, we used CompuSyn software to calculate the combination index $(\mathrm{Cl})$ and dose reduction index (DRI) (Figure $4 \mathrm{~B}$, Table 2 and Table 3). The results showed that the $\mathrm{Cl}$ value of $\mathrm{DMAMCL}$ and gemcitabine at $E D_{50}$, $\mathrm{ED}_{75}$ and $\mathrm{ED}_{90}$ were $0.63,0.69$ and 0.77 in BxPC-3 cells, which exhibits the best synergistic effects in terms of reduction of cell viability based on the Chou-Talalay analysis. For MCL and gemcitabine, the best synergistic effect was found in PANC-1 cells, which is $0.43,0.46$ and 0.89 at $E D_{50}, E_{75}$ and $E D_{90}$. Furthermore, under the treatment of DMAMCL at $5 \mu \mathrm{M}$, the $\mathrm{IC}_{50}$ of gemcitabine was found decreased from 4.21 to $2.85 \mu \mathrm{M}$ in AsPC-1 cells and from 2.33 to $0.75 \mu \mathrm{M}$ in PANC-1 cells, indicated that DMAMCL could increase the efficacy of gemcitabine on pancreatic cancer cell proliferation (Table 4 and Figure 5).

\section{DMAMCL enhances the pro-apoptosis effect of gemcitabine in pancreatic cancer cells}

In order to further verify whether DMAMCL enhance the pro-apoptosis effect of gemcitabine in pancreatic cancer cells, the early and late apoptosis was analyzed by flow cytometry analysis. Dual-labeled fluorescence activated cell sorting (FACS) analysis (Annexin V and PI) was used to measure early and late apoptosis. Annexin $\mathrm{V}$ detects early apoptosis, whereas both PI and Annexin V detect late apoptosis. By $48 \mathrm{~h}$ treatment, compared with single treatment (20 $\mu \mathrm{M}$ DMAMCL, $10 \mu \mathrm{M} \mathrm{MCL}, 2.5 \mu \mathrm{M}$ gemcitabine), 


\section{ANXA2 mediated PI3K/AKT inhibition contributes to the synergistic effect of DMAMCL and gemcitabine}

The phosphoinositide 3-kinase/Akt signalling pathway is a recognized key parameter in numerous cellular processes such as proliferation, cell cycle and angio-genesis, and is frequently activated in pancreatic cancer and especially in gemcitabine resistance [28]. Akt kinase can be activated by phosphorylation on Thr 308 or Ser 473 and active-Akt will promote cell growth and survival to apoptotic insults $[29,30]$. It was also proved that DMAMCL has the ability to inhibit of PI3K/AKT and induce apoptosis in hepatocellular carcinoma [25]. To investigate whether the effect of DMAMCL on ANXA2 further influence the PI3K/AKT signal pathway, we detected the expression and the phosphorylation of Akt on ser473. Western blot results demonstrated that compared with DMAMCL or gemcitabine alone, DMAMCL + gemcitabine exhibited more potent inhibition of AKT signaling pathway (Figure 6B), which suggested that the synergistic effect of DMAMCL and gemcitabine could be partly mediated by ANXA2AKT pathway.

\section{Discussion}

Gemcitabine is the standard treatment for advanced pancreatic adenocarcinoma, but the efficacy of this reagent is still limited. ANXA2, as a tumor-associated protein, has been proved promoting cancer progression including proliferation, invasion, and metastasis in various cancer types [8-13]. In addition, ANXA2 was also reported to mediate gemcitabine resistance in pancreatic cancer $[9,16,31,32]$. Thus, ANXA2-targeted agent is anticipated to be a novel treatment for pancreatic cancer.

DMAMCL has been shown to exert potent anticancer properties on multiple cancers, but has not yet in pancreatic cancer. Herein, we explored its effect on three pancreatic cancer cell lines and identified ANXA2 was a novel target for its property. Meanwhile, we found that gemcitabine in combination with DMAMCL could inhibit tumor growth and induce apoptosis more effectively than gemcitabine or DMAMCL alone.

To clarify the mechanisms of gemcitabine resistance induced by ANXA2 overexpression, Kagawa et al. analyzed the signaling pathways up-regulated in the gemcitabine-resistant cell lines with overexpressed ANXA2. Bio-Plex phosphorylation protein assay showed up-regulation of p-Akt in GEM-MIA PaCa-2 cells in which ANXA2 is highly expressed. Inhibition of p-Akt through mTOR inhibitor canceled gemcitabine resistance in GEM-MIA PaCa-2 cells [28], indicated ANXA2-mediated activation of Akt accounting for the low response of gemcitabine [15, 33-35]. Our previous work has demonstrated that DMAMCL can significantly inhibit the level of p-AKT in different cancer cells $[20,25]$. In this study, we also observed that the inhibition of DMAMCL on p-AKT was significantly reduced in AsPC-1 (sh-ANXA2) cells. Thus, we 
supposed that the synergistic mechanism of enhanced efficacy of gemcitabine may be ANXA2-AKT pathway inhibition induced by DMAMCL.

In conclusion, our work revealed that DMAMCL could suppress pancreatic cancer by targeting ANXA2. The binding of DMAMCL on C132 of ANXA2 might down-regulate p-AKT that offset the activation of $p$ AKT by gemcitabine. DMAMCL in combination with gemcitabine exhibits a synergistic cytotoxic effect, which may be used as a more effective treatment for pancreatic cancer.

\section{Abbreviations}

DMAMCL, Dimethylaminomicheliolide; ANXA2, Annexin A2; PCNA, Proliferating cell nuclear antigen ; GEM-, Gemcitabine-resistant; WT-, Wild type; sh ANXA2, ANXA2 knock down; PI3K, Phosphoinositide 3kinase; AKT, Protein kinase B; mTOR, mammalian target of rapamycin; NFkB, Nuclear factor kappa B; ROS, Reactive oxygen species; MTT, Thiazolyl Blue Tetrazolium Bromide; Cys, Cysteine; MCL, micheliolide; EDTA, Ethylene Diamine Tetraacetic Acid; C132G, Mutation of Cysteine132 to Glycine132; $\mathrm{Cl}$,calculate the combination index; DRI, dose reduction index; PMSF, Phenylmethylsulfonyl fluoride; IPTG, Isopropyl-betaD-thiogalactopyranoside.

\section{Declarations}

\section{Acknowledgments}

No applicable.

\section{Author contributions}

J.L. and M.Y.Z. developed the concept and designed the study. K.H.L., J.S.G., N.L., J.Y.W. M.K.W., Y.W.Z. and H.J. carried the experiments. Y.L.L., W.Z.F., F.Z.H. C.Z.Z. and L.Y.L. provided technical support and conceptual advice. K.H.L. and M.Y.Z. wrote the manuscript. All authors read and approved the final manuscript.

\section{Funding}

This work was supported by grants from the National Science Fund for Distinguished Young Scholars of China (NSFC: 81625021), the Natural Science Foundation of China (NSFC: 82073879).

\section{Availability of data and materials}

The datasets used and/or analyzed during the current study are available from the corresponding author on reasonable request. 


\section{Ethics approval and consent to participate}

Not applicable.

\section{Consent for publication}

Not applicable.

\section{Competing interests}

The authors declare that they have no known competing financial interests.

\section{Author details}

${ }^{1}$ State Key Laboratory of Medicinal Chemical Biology, College of Pharmacy and College of Chemistry, Nankai University, Haihe Education Park, 38 Tongyan Road, Tianjin 300353, China

${ }^{2}$ College of Medicine and Nursing, Dezhou University, Dezhou, 253023, China.

${ }^{3}$ Department of Gastroenterology, PLA Strategic Support Force Medical Center, Beijing, 100101, China.

${ }^{4}$ Department of Colorectal Surgery, Tianjin Union Medical Center, Tianjin, 300121, China.

\section{References}

1. Ferlay J, Soerjomataram I, Dikshit R, Eser S, Mathers C, Rebelo M, et al., Cancer incidence and mortality worldwide: sources, methods and major patterns in GLOBOCAN 2012. Int J Cancer 2015;136(5):E359-386. http://doi.org/10.1002/ijc.29210.

2. Jemal A, Siegel R, Ward E, Hao Y, Xu J, Murray T, et al., Cancer statistics, 2008. CA Cancer J. Clin. 2008;58(2):71-96. http://doi.org/10.3322/ca.2007.0010.

3. Wang Y, Hu G F, Zhang Q Q, Tang N, Guo J, Liu L Y, et al., Efficacy and safety of gemcitabine plus erlotinib for locally advanced or metastatic pancreatic cancer: a systematic review and metaanalysis. Drug Des. Devel. Ther. 2016;10(1961-1972. http://doi.org/10.2147/dddt.s105442.

4. Ducreux M, Cuhna A S, Caramella C, Hollebecque A, Burtin P, Goéré D, et al., Cancer of the pancreas: ESMO Clinical Practice Guidelines for diagnosis, treatment and follow-up. Ann. Oncol. 2015;26 Suppl 5(v56-68. http://doi.org/10.1093/annonc/mdv295.

5. Yip-Schneider M T, Nakshatri H, Sweeney C J, Marshall M S, Wiebke E A, Schmidt C M, Parthenolide and sulindac cooperate to mediate growth suppression and inhibit the nuclear factor-kappa $B$ 
pathway in pancreatic carcinoma cells. Mol. Cancer Ther. 2005;4(4):587-594.

http://doi.org/10.1158/1535-7163.mct-04-0215.

6. Heinemann V, Gemcitabine: progress in the treatment of pancreatic cancer. Oncology 2001;60(1):818. http://doi.org/10.1159/000055290.

7. Bharadwaj A, Bydoun M, Holloway R, Waisman D, Annexin A2 heterotetramer: structure and function. Int. J. Mol. Sci. 2013;14(3):6259-6305. http://doi.org/10.3390/ijms14036259.

8. Lokman N A, Elder A S, Ween M P, Pyragius C E, Hoffmann P, Oehler M K, et al., Annexin A2 is regulated by ovarian cancer-peritoneal cell interactions and promotes metastasis. Oncotarget 2013;4(8):1199-1211. http://doi.org/10.18632/oncotarget.1122.

9. Chen C Y, Lin Y S, Chen C L, Chao P Z, Chiou J F, Kuo C C, et al., Targeting annexin A2 reduces tumorigenesis and therapeutic resistance of nasopharyngeal carcinoma. Oncotarget 2015;6(29):26946-26959. http://doi.org/10.18632/oncotarget.4521.

10. Zhai H, Acharya S, Gravanis I, Mehmood S, Seidman R J, Shroyer K R, et al., Annexin A2 promotes glioma cell invasion and tumor progression. J Neurosci 2011;31(40):14346-14360. http://doi.org/10.1523/jneurosci.3299-11.2011.

11. Zhang H J, Yao D F, Yao M, Huang H, Wang L, Yan M J, et al., Annexin A2 silencing inhibits invasion, migration, and tumorigenic potential of hepatoma cells. World J. Gastroenterol. 2013;19(24):37923801. http://doi.org/10.3748/wjg.v19.i24.3792.

12. Zheng L, Foley K, Huang L, Leubner A, Mo G, Olino K, et al., Tyrosine 23 phosphorylation-dependent cell-surface localization of annexin A2 is required for invasion and metastases of pancreatic cancer. PLoS One 2011;6(4):e19390. http://doi.org/10.1371/journal.pone.0019390.

13. Sharma M R, Koltowski L, Ownbey R T, Tuszynski G P, Sharma M C, Angiogenesis-associated protein annexin II in breast cancer: selective expression in invasive breast cancer and contribution to tumor invasion and progression. Exp Mol Pathol 2006;81(2):146-156.

http://doi.org/10.1016/j.yexmp.2006.03.003.

14. Vishwanatha J K, Chiang Y, Kumble K D, Hollingsworth M A, Pour P M, Enhanced expression of annexin II in human pancreatic carcinoma cells and primary pancreatic cancers. Carcinogenesis 1993;14(12):2575-2579. http://doi.org/10.1093/carcin/14.12.2575.

15. Jung H, Kim J S, Kim W K, Oh K J, Kim J M, Lee H J, et al., Intracellular annexin A2 regulates NF-KB signaling by binding to the $\mathrm{p} 50$ subunit: implications for gemcitabine resistance in pancreatic cancer. Cell Death Dis. 2015;6(1):e1606. http://doi.org/10.1038/cddis.2014.558.

16. Takano S, Togawa A, Yoshitomi H, Shida T, Kimura F, Shimizu H, et al., Annexin Il overexpression predicts rapid recurrence after surgery in pancreatic cancer patients undergoing gemcitabineadjuvant chemotherapy. Ann. Surg. Oncol. 2008;15(11):3157-3168. http://doi.org/10.1245/s10434008-0061-5.

17. Wang Y, Zhang J, Yang Y, Liu Q, Xu G, Zhang R, et al., ROS generation and autophagosome accumulation contribute to the DMAMCL-induced inhibition of glioma cell proliferation by regulating 
the ROS/MAPK signaling pathway and suppressing the Akt/mTOR signaling pathway. Onco Targets Ther. 2019;12(1867-1880. http://doi.org/10.2147/ott.s195329.

18. Li Q, Sun Y, Liu B, Li J, Hao X, Ge W, et al., ACT001 modulates the NF-KB/MnSOD/ROS axis by targeting IKK $\beta$ to inhibit glioblastoma cell growth. J. Mol. Med. (Berl.) 2020;98(2):263-277. http://doi.org/10.1007/s00109-019-01839-0.

19. Guo J, Xue Q, Liu K, Ge W, Liu W, Wang J, et al., Dimethylaminomicheliolide (DMAMCL) Suppresses the Proliferation of Glioblastoma Cells via Targeting Pyruvate Kinase 2 (PKM2) and Rewiring Aerobic Glycolysis. Front. Oncol. 2019;9(993. http://doi.org/10.3389/fonc.2019.00993.

20. Xi X, Liu N, Wang Q, Chu Y, Yin Z, Ding Y, et al., ACT001, a novel PAl-1 inhibitor, exerts synergistic effects in combination with cisplatin by inhibiting PI3K/AKT pathway in glioma. Cell Death Dis. 2019;10(10):757. http://doi.org/10.1038/s41419-019-1986-2.

21. Li J, Li S, Guo J, Li Q, Long J, Ma C, et al., Natural Product Micheliolide (MCL) Irreversibly Activates Pyruvate Kinase M2 and Suppresses Leukemia. J. Med. Chem. 2018;61(9):4155-4164. http://doi.org/10.1021/acs.jmedchem.8b00241.

22. Xu N, Hua Z, Ba G, Zhang S, Liu Z, Thiele C J, et al., The anti-tumor growth effect of a novel agent DMAMCL in rhabdomyosarcoma in vitro and in vivo. J. Exp. Clin. Cancer Res. 2019;38(1):118. http://doi.org/10.1186/s13046-019-1107-1.

23. Zhang Q, Lu Y, Ding Y, Zhai J, Ji Q, Ma W, et al., Guaianolide sesquiterpene lactones, a source to discover agents that selectively inhibit acute myelogenous leukemia stem and progenitor cells. J. Med. Chem. 2012;55(20):8757-8769. http://doi.org/10.1021/jm301064b.

24. Dong T, Li C, Wang X, Dian L, Zhang X, Li L, et al., Ainsliadimer A selectively inhibits IKKa/ $\beta$ by covalently binding a conserved cysteine. Nat Commun 2015;6(6522. http://doi.org/10.1038/ncomms7522.

25. Yao S, Ye J, Yin M, Yu R, DMAMCL exerts antitumor effects on hepatocellular carcinoma both in vitro and in vivo. Cancer Lett. 2020;483(87-97. http://doi.org/10.1016/j.canlet.2020.04.003.

26. Babaei G, Aliarab A, Abroon S, Rasmi Y, Aziz S G, Application of sesquiterpene lactone: A new promising way for cancer therapy based on anticancer activity. Biomed. Pharmacother. 2018;106(239-246. http://doi.org/10.1016/j.biopha.2018.06.131.

27. Zhang X, Liu S, Guo C, Zong J, Sun M Z, The association of annexin A2 and cancers. Clin. Transl. Oncol. 2012;14(9):634-640. http://doi.org/10.1007/s12094-012-0855-6.

28. Kagawa S, Takano S, Yoshitomi H, Kimura F, Satoh M, Shimizu H, et al., Akt/mTOR signaling pathway is crucial for gemcitabine resistance induced by Annexin II in pancreatic cancer cells. J. Surg. Res. 2012;178(2):758-767. http://doi.org/10.1016/j.jss.2012.05.065.

29. Brunet A, Bonni A, Zigmond M J, Lin M Z, Juo P, Hu L S, et al., Akt promotes cell survival by phosphorylating and inhibiting a Forkhead transcription factor. Cell 1999;96(6):857-868. http://doi.org/10.1016/s0092-8674(00)80595-4.

30. Martelli A M, Nyakern M, Tabellini G, Bortul R, Tazzari P L, Evangelisti C, et al., Phosphoinositide 3kinase/Akt signaling pathway and its therapeutical implications for human acute myeloid leukemia. 
Leukemia 2006;20(6):911-928. http://doi.org/10.1038/sj.leu.2404245.

31. Zhang Z D, Li Y, Fan Q, Zhao B, Tan B, Zhao X F, Annexin A2 is implicated in multi-drug-resistance in gastric cancer through p38MAPK and AKT pathway. Neoplasma 2014;61(6):627-637. http://doi.org/10.4149/neo_2014_078.

32. Zhang F, Zhang H, Wang Z, Yu M, Tian R, Ji W, et al., P-glycoprotein associates with Anxa2 and promotes invasion in multidrug resistant breast cancer cells. Biochem Pharmacol 2014;87(2):292302. http://doi.org/10.1016/j.bcp.2013.11.003.

33. Gong X G, Lv Y F, Li X Q, Xu F G, Ma Q Y, Gemcitabine resistance induced by interaction between alternatively spliced segment of tenascin-C and annexin A2 in pancreatic cancer cells. Biol. Pharm. Bull. 2010;33(8):1261-1267. http://doi.org/10.1248/bpb.33.1261.

34. Chaturvedi M M, Sung B, Yadav V R, Kannappan R, Aggarwal B B, NF-kB addiction and its role in cancer: 'one size does not fit all'. Oncogene 2011;30(14):1615-1630. http://doi.org/10.1038/onc.2010.566.

35. Castaldo S A, Ajime T, Serrão G, Anastácio F, Rosa J T, Giacomantonio C A, et al., Annexin A2 Regulates AKT Upon H囚O囚-Dependent Signaling Activation in Cancer Cells. Cancers (Basel) 2019;11(4).http://doi.org/10.3390/cancers11040492.

\section{Tables}

\section{Table 1}

Summary of $\mathrm{IC}_{50}$ values of DMAMCL or MCL on AsPC-1, BxPC-3 and PANC-1 cells. Error bars, mean \pm s.e.m., $n=3$ biological replicates.

\begin{tabular}{|llll|}
\hline $\mathrm{IC}_{50}(\mu \mathrm{M})$ & AsPC-1 & BxPC-3 & PANC-1 \\
\hline DMAMCL & $37.76 \pm 1.58$ & $35.83 \pm 1.55$ & $19.66 \pm 1.29$ \\
\hline MCL & $18.79 \pm 1.27$ & $11.73 \pm 1.07$ & $6.08 \pm 0.78$ \\
\hline
\end{tabular}

Table 2

The combination index $(\mathrm{Cl})$ and dose reduction index (DRI) of DMAMCL and gemcitabine in AsPC-1, BxPC-3 and PANC-1 cells. 


\begin{tabular}{|lllll|}
\hline & & Cl & DMAMCL DRI & Gemcitabine DRI \\
\hline AsPC-1 & $E_{50}$ & 0.52639 & 4.61724 & 3.22777 \\
& $E_{75}$ & 0.96749 & 1.28252 & 5.32550 \\
\hline & $E_{90}$ & 2.92089 & 0.35624 & 8.78654 \\
\hline BXPC-3 & $E_{50}$ & 0.62771 & 3.67495 & 2.81219 \\
\hline & $E D_{75}$ & 0.69377 & 3.3954. & 2.50470 \\
\hline \multirow{2}{*}{ PANC-1 } & $E_{90}$ & 0.76703 & 3.13712 & 2.23083 \\
\hline & $E_{50}$ & 0.70755 & 2.72004 & 2.94199 \\
\hline & $E_{75}$ & 1.39051 & 0.77215 & 10.4798 \\
\hline
\end{tabular}

Table 3

The combination index $(\mathrm{Cl})$ and dose reduction index (DRI) of MCL and gemcitabine in AsPC-1, BxPC-3 and PANC- 1 cells.

\begin{tabular}{|lllll|}
\hline & & Cl & MCL & Gemcitabine DRI \\
& & & DRI & \\
\hline AsPC-1 & $E_{50}$ & 0.45723 & 5.9571 & 3.45589 \\
& $E_{75}$ & 0.84774 & 1.48603 & 5.72056 \\
\hline & $E_{90}$ & 2.80320 & 0.37070 & 9.46929 \\
\hline BxPC-3 & $E_{50}$ & 1.07877 & 2.01259 & 1.71853 \\
\hline & $E_{75}$ & 1.33391 & 1.35353 & 1.68039 \\
\hline & $E_{90}$ & 1.70715 & 0.91029 & 1.64311 \\
\hline PANC-1 & $E_{50}$ & 0.43061 & 5.48189 & 4.02922 \\
\hline & $E_{75}$ & 0.46706 & 2.50073 & 14.8865 \\
\hline & $E_{90}$ & 0.89477 & 1.14078 & 55.0006 \\
\hline
\end{tabular}




\section{Table 4}

Summary of $\mathrm{IC}_{50}$ values of gemcitabine on AsPC-1 and PANC-1 cells when treated with or without $5 \mu \mathrm{M}$ DMAMCL. Error bars, mean \pm s.e.m., $\mathrm{n}=3$ biological replicates.

\begin{tabular}{|lll|}
\hline $\mathrm{IC}_{50}(\mu \mathrm{M})$ & AsPC-1 & PANC-1 \\
\hline Gemcitabine & $4.21 \pm 0.41$ & $2.33 \pm 0.50$ \\
\hline $\begin{array}{l}\text { Gemcitabine } \\
\text { (DMAMCL } 5 \mu \mathrm{M})\end{array}$ & $2.85 \pm 0.39$ & $0.75 \pm 0.43$ \\
\hline
\end{tabular}

Figures 
A
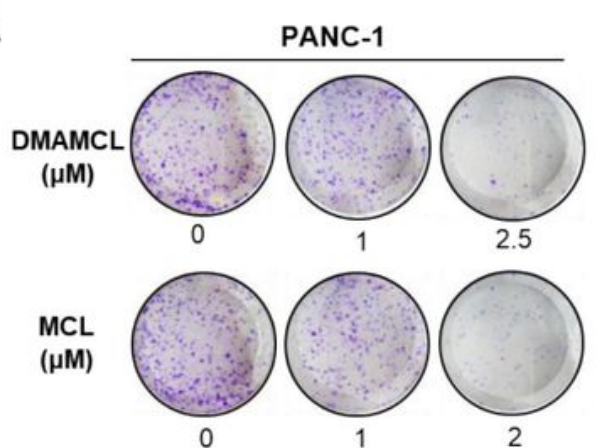

B
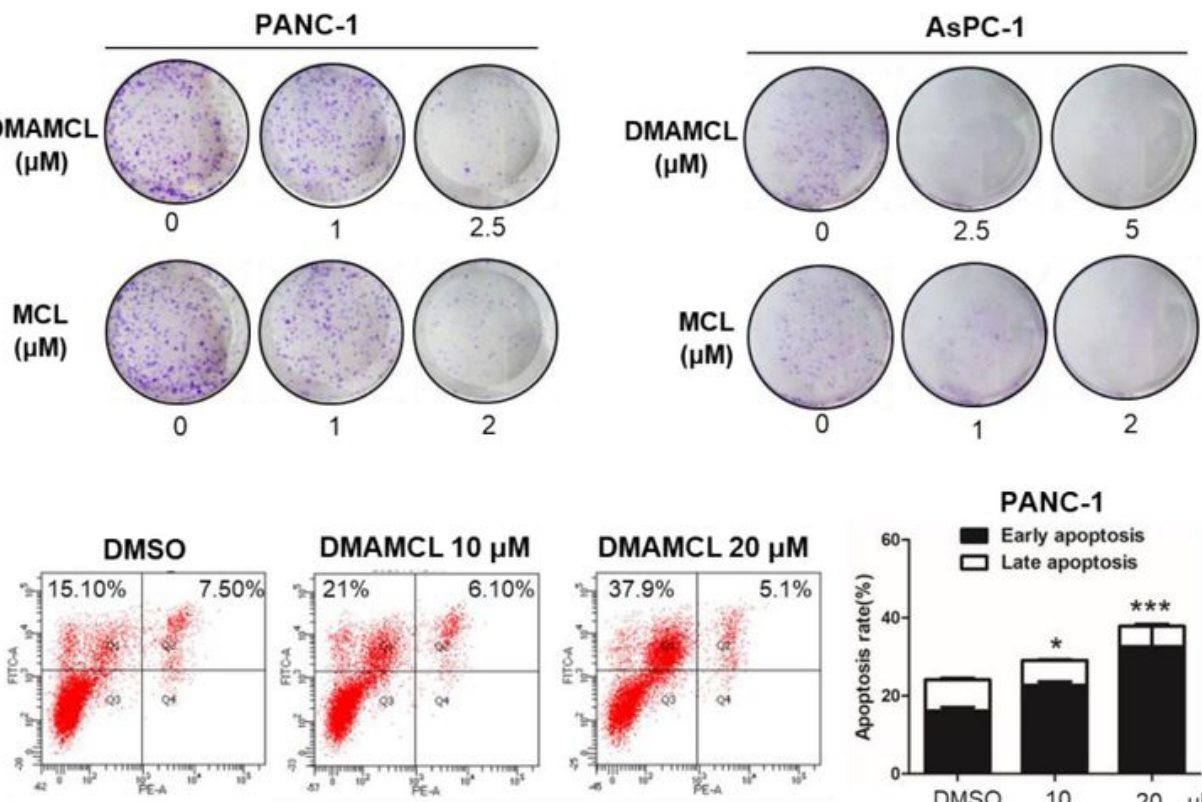

\section{PANC-1}
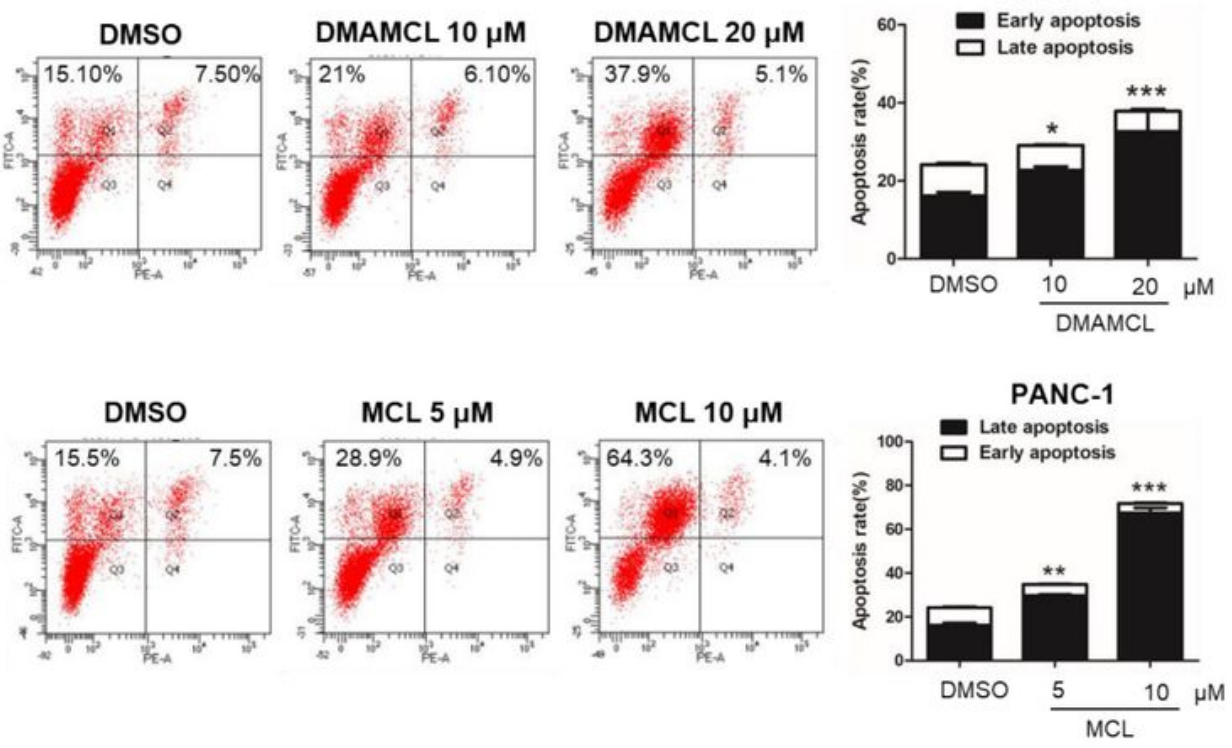

C
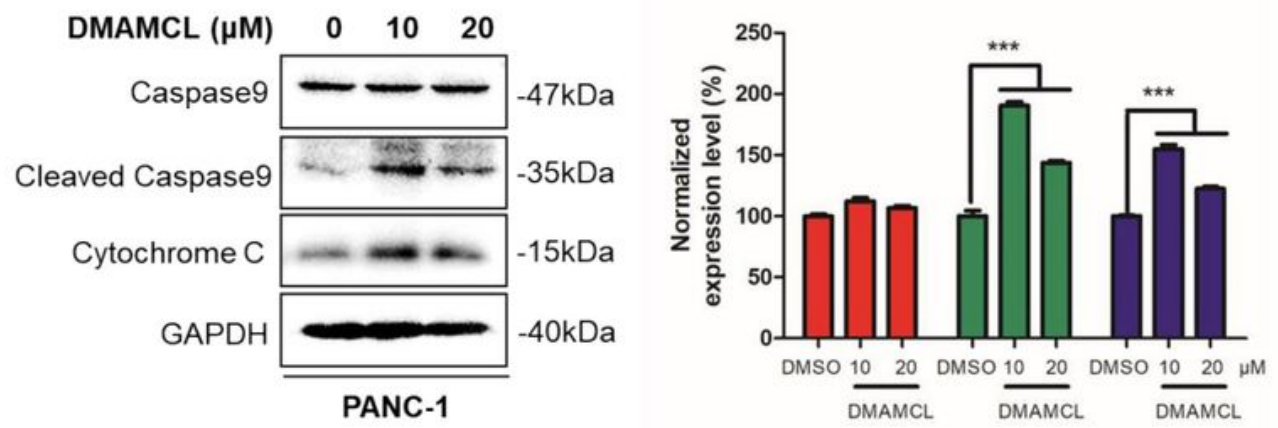

\section{Figure 1}

DMAMCL inhibited foci formation and induced cell apoptosis in pancreatic cancer cells. (A) Colony formation assays of PANC-1 and AsPC- 1 cells (2000 cells/well) treated with DMAMCL or MCL for 14 days. (B) Apoptosis assays of PANC-1 cells (2×105 cells/well) treated with different doses of DMAMCL or MCL for 48 h. (C) PANC-1 cells were treated with various doses of DMAMCL for $48 \mathrm{~h}$, and then total cellular lysates were subjected to western blot analysis with cytochrome and caspase-9 antibodies. 
GAPDH was used as a loading control. Error bars, mean \pm s.e.m., $n=3$ biological replicates. ${ }^{\star} \mathrm{P}<0.05$, $* \star \mathrm{P}$ $<0.01, * \star \star P<0.001$.

A

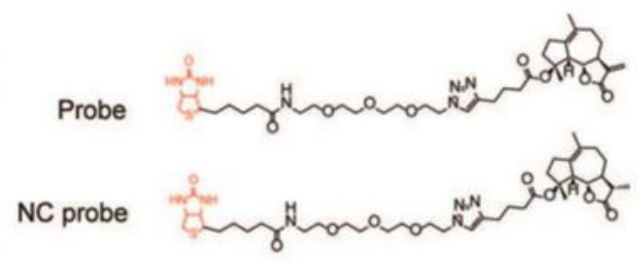

C $\begin{array}{llllllll}\mathrm{NC}(\mu \mathrm{M}) & 10 & - & - & - & - & - & - \\ \text { Probe }(\mu \mathrm{M}) & - & 0 & 1 & 2.5 & 5 & 10 & 20\end{array}$

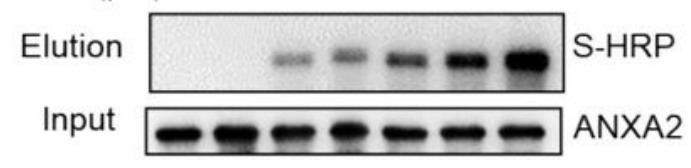

$\mathbf{E}$

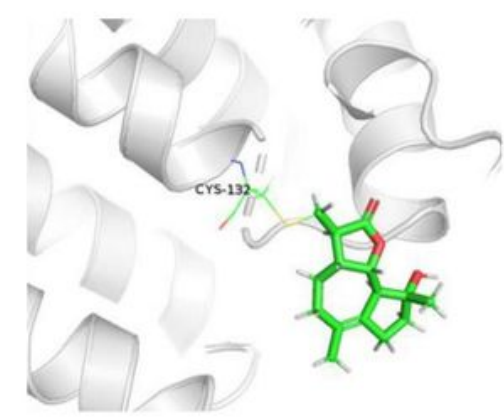

$\mathbf{F}$

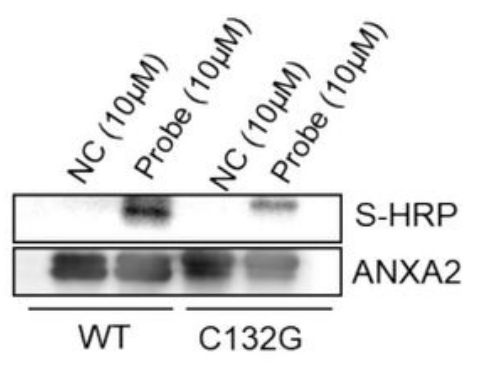

B
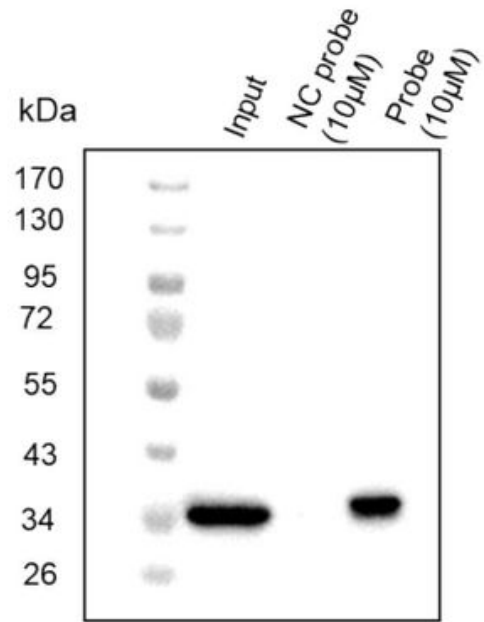

D
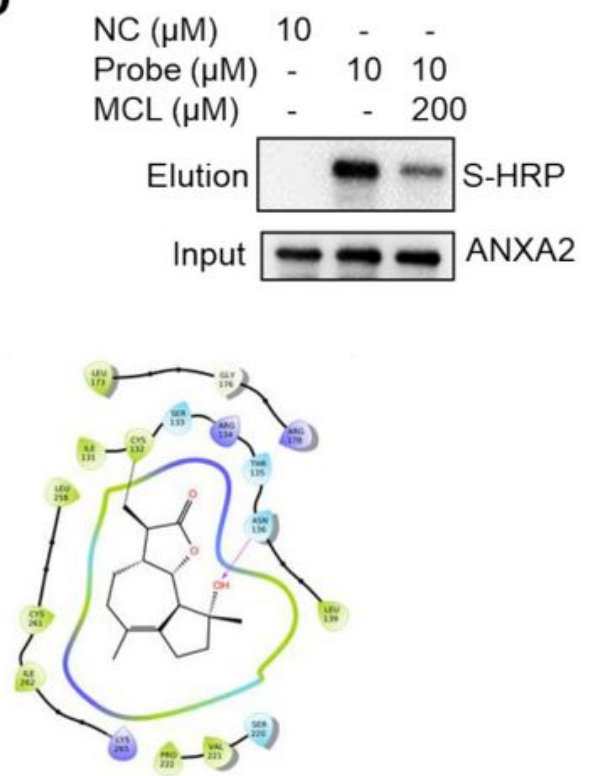

Figure 2

DMAMCL directly targeted Cys132 site of ANXA2. (A) Chemical structures of biotin-conjugated MCL (MCL-biotin,Probe) and biotin-conjugated single-bond MCL (MCL-S-biotin, NC probe). (B) Western blot detection of ANXA2 proteins from probe-cell lysis mixture. (C) NC probe and probes with different 
concentrations were incubated with BxPC-3 cell lysates overnight at $4^{\circ} \mathrm{C}$, and biotin was detected by western blot. (D) The BxPC-3 cell lysates were incubated with Probe in the absence or presence of a 20fold excess of unlabeled $\mathrm{MCL}$ overnight at $4^{\circ} \mathrm{C}$, and biotin was detected by western blot. (E) Molecular docking assays of MCL interacting with ANXA2. (F) ANXA2-WT and ANXA2-C132G mutation were incubated with probe overnight at $4^{\circ} \mathrm{C}$, and biotin was detected by western blot.

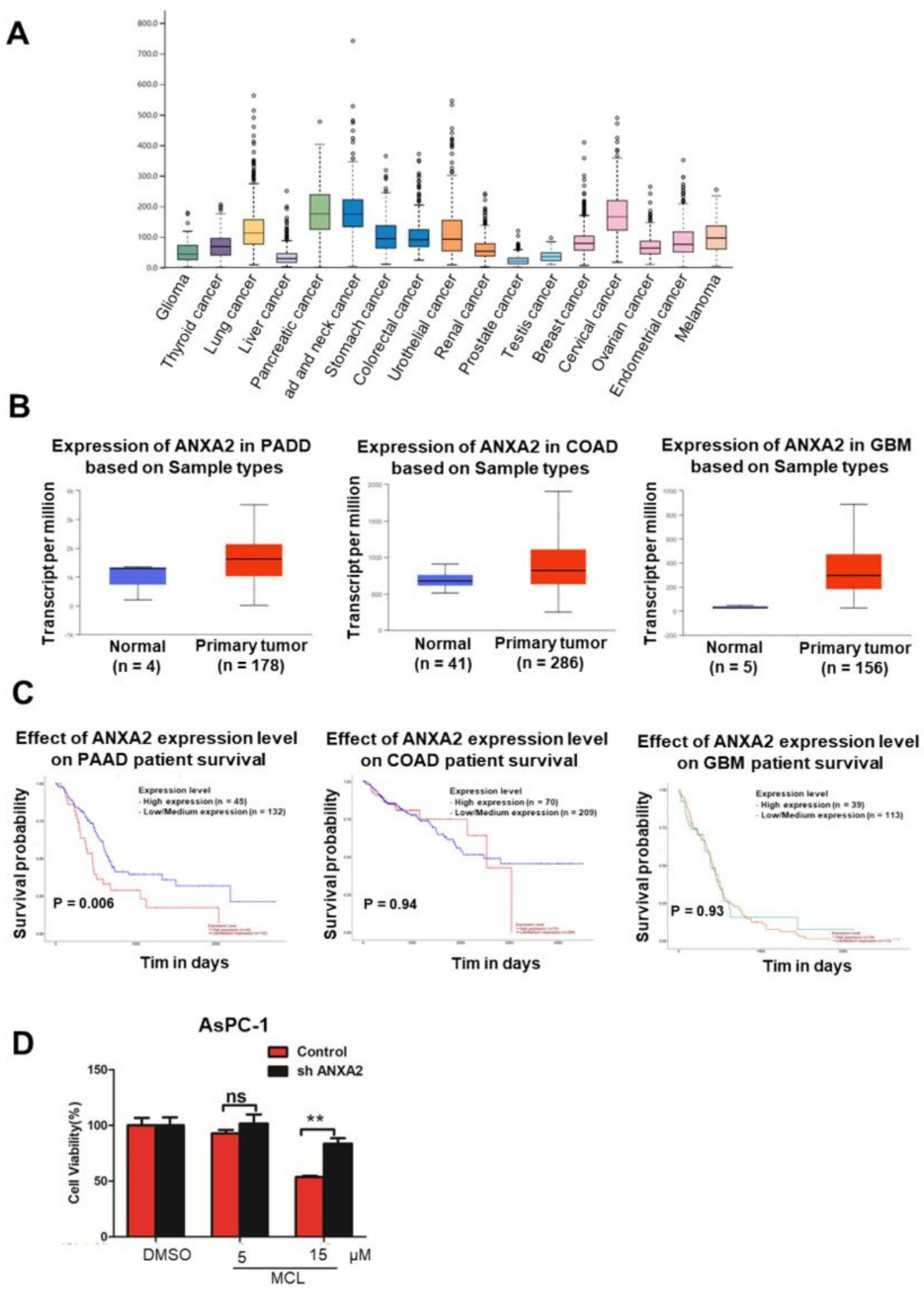

Figure 3 
HPA database analysis and dose inhibition assays. (A) Expression analysis of ANXA2 in all types of cancer. (B) Expression analysis of ANXA2 in normal and glioma (GBM), colorectal (COAD) and pancreatic cancer (PADD) patients. (C) Survival analysis of ANXA2 in patients with glioma (GBM), colorectal (COAD) and pancreatic cancer (PADD). (D) Dose inhibition assays on AsPC-1-WT and AsPC-1-sh ANXA2. Error

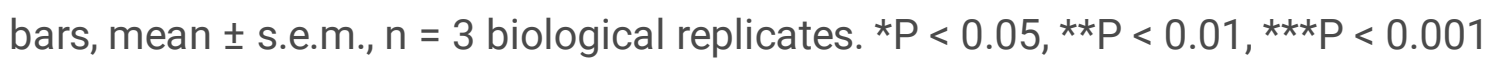
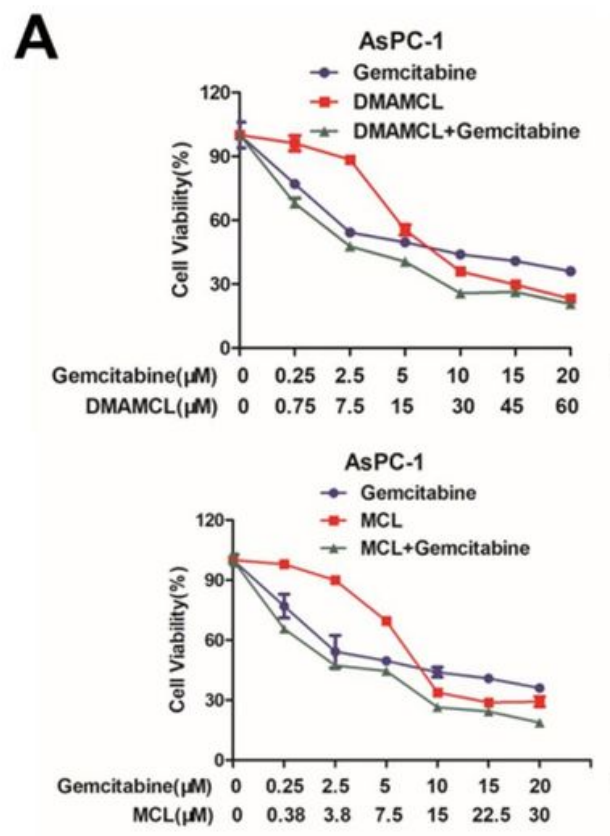

B

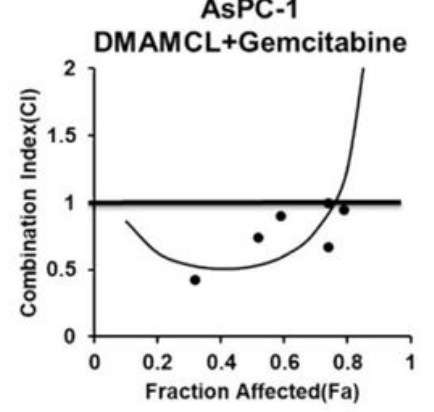

AsPC-1

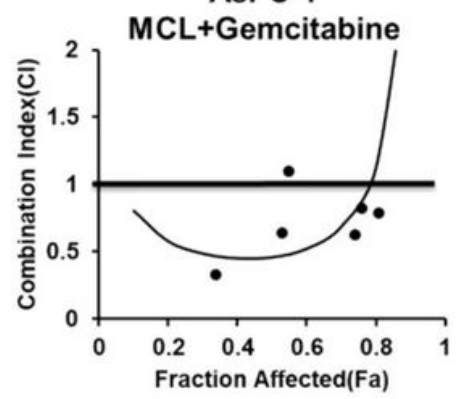

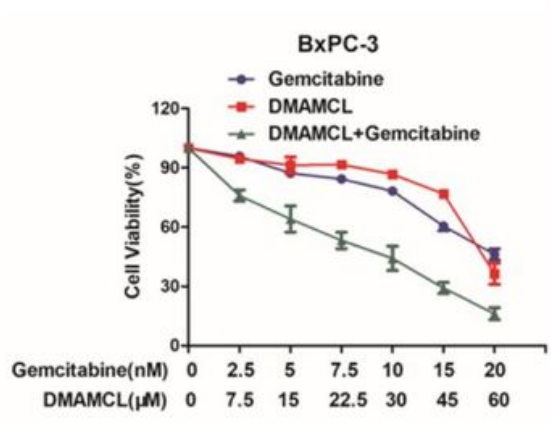

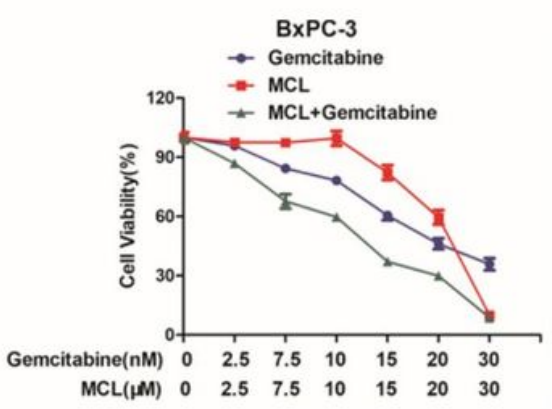

BxPC-3

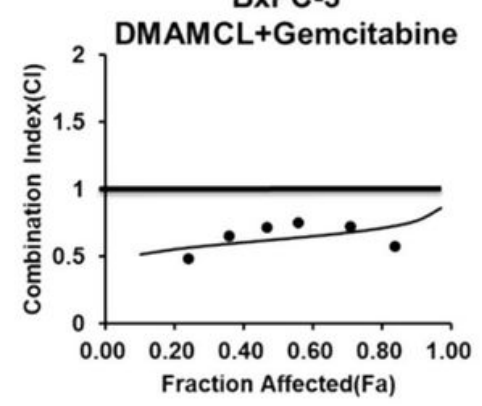

BxPC-3

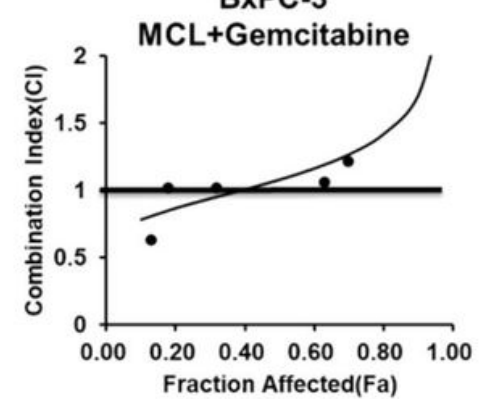

PANC-1

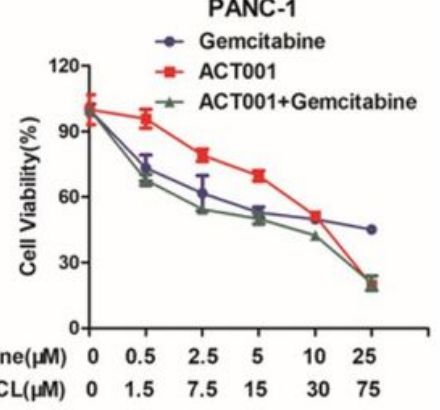

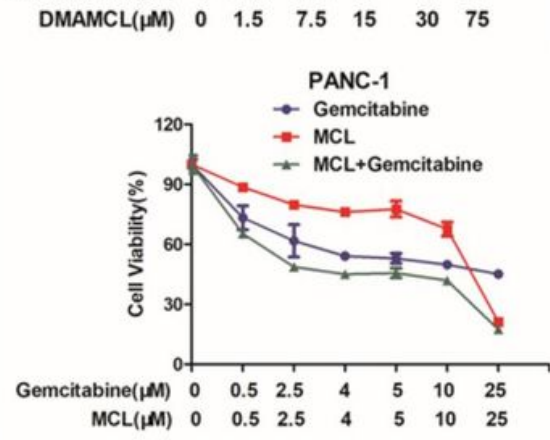

PANC-1

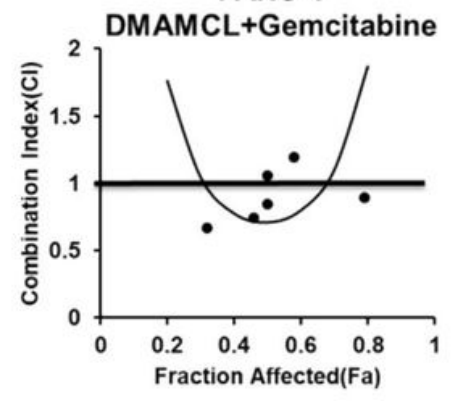

PANC-1

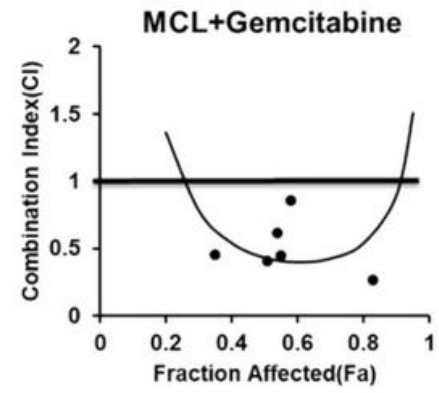

\section{Figure 4}

Synergistic combination effects between DMAMCL (MCL) and gemcitabine. (A) MTT assays of the AsPC1, BxPC-3 and PANC-1 cells (4000 cells/well) were treated with different concentrations of DMAMCL 
(MCL), gemcitabine or DMAMCL (MCL) + gemcitabine (mixed in proportion) for $72 \mathrm{~h}$. (B) The Chou Talalay analysis of AsPC-1, BxPC-3 and PANC-1 cells treated with DMAMCL (MCL) and gemcitabine for 72 h. Error bars, mean \pm s.e.m., $n=3$ biological replicates.

PANC-1

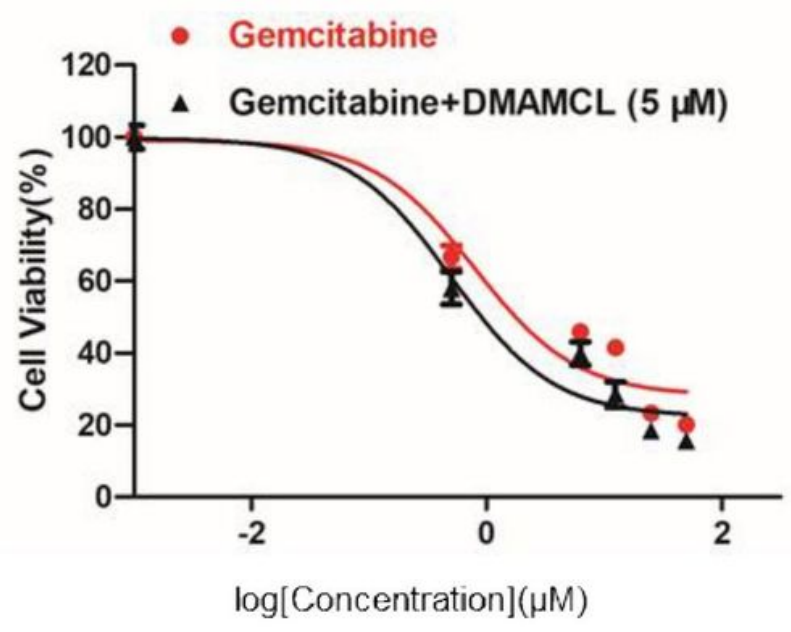

AsPC-1

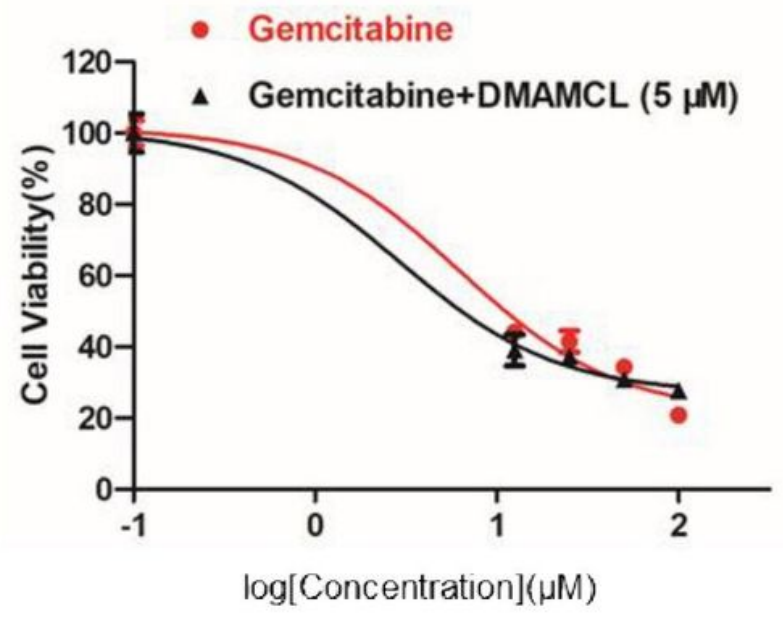

\section{Figure 5}

DMAMCL enhances the sensitivity of gemcitabine in pancreatic cancer cells. MTT assays of AsPC-1 and PANC-1 cells (4000 cells/well) treated with gemcitabine or gemcitabine + DMAMCL $(5 \mu \mathrm{M})$ for $72 \mathrm{~h}$. 

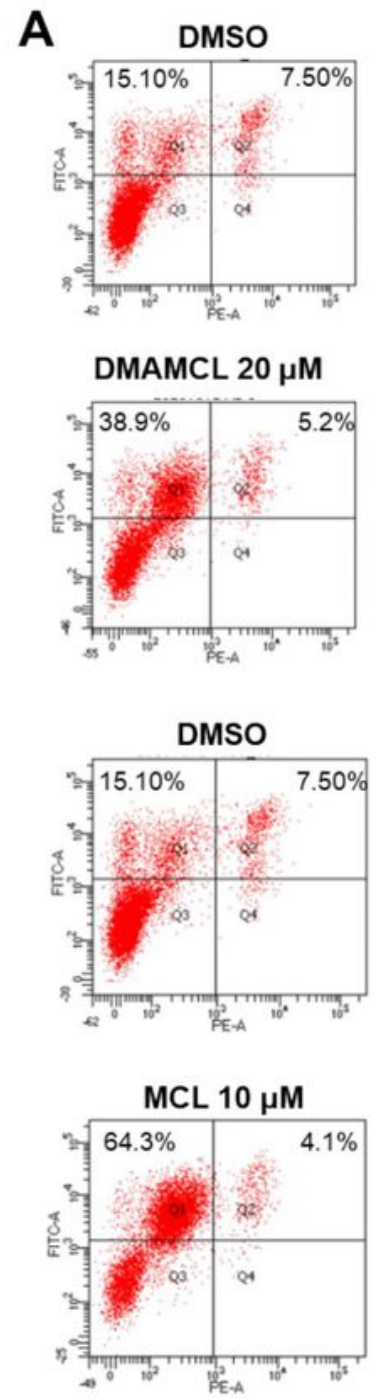

\section{B}

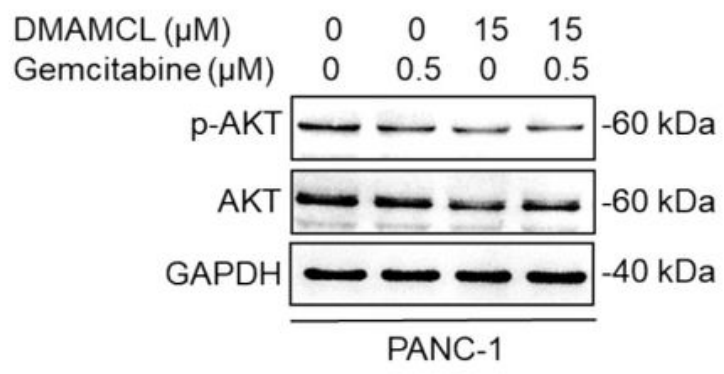

+ DMAMCL $20 \mu \mathrm{M}$
PANC-1

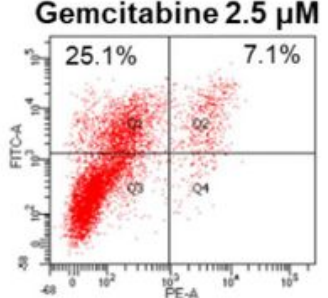

Gemcitabine $2.5 \mu \mathrm{M}$

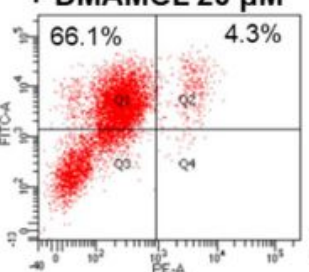

DMAMCL 0

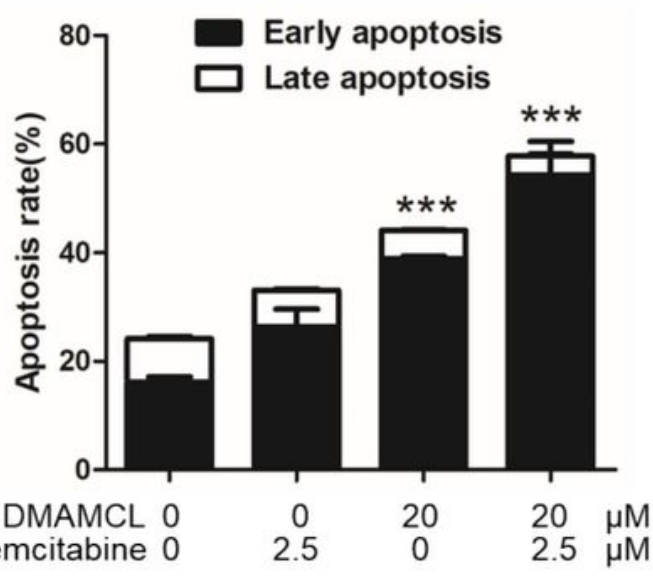

PANC-1

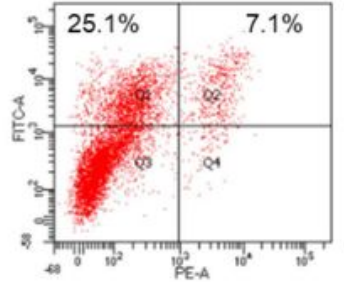

Gemcitabine $2.5 \mu \mathrm{M}$

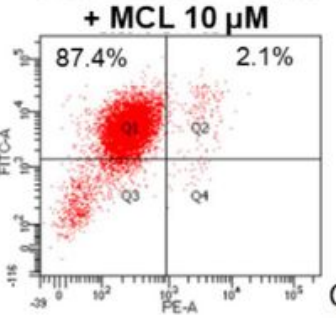

Gemcitabine 0
Early apoptosis

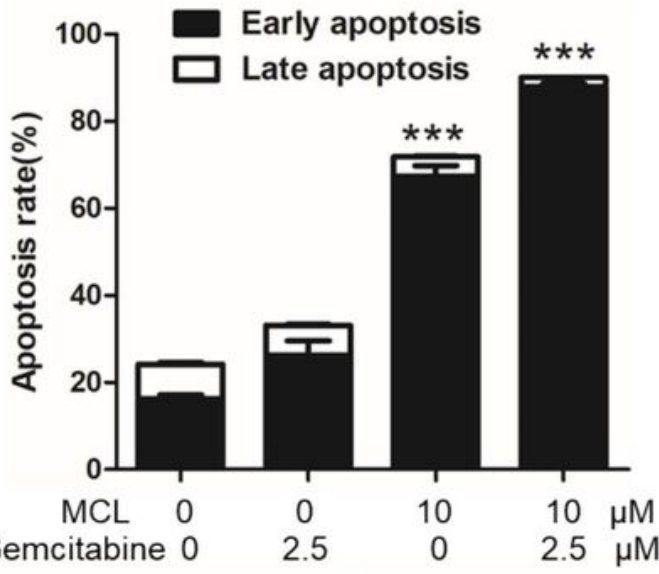

$\square \mathrm{p}-\mathrm{AKT}$

$\square$ AKT

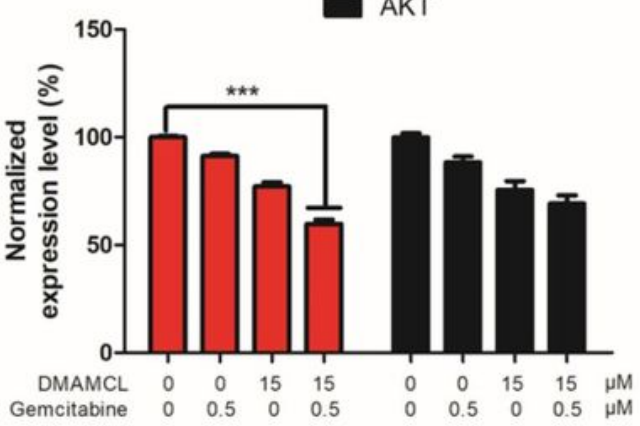

\section{Figure 6}

DMAMCL combined with gemcitabine inhibit the AKT pathway and induce apoptosis in pancreatic cancer cells. (A) PANC-1 cells were treated with DMAMCL (MCL), gemcitabine or DMAMCL (MCL) + gemcitabine for $48 \mathrm{~h}$ and cellular apoptosis was measured by FITC coupled with Annexin-V apoptosis detection kit. (B) The protein levels of AKT/p-AKT in PANC- 1 cells analyzed by western blot. Error bars, mean \pm s.e.m., $n=3$ biological replicates. ${ }^{*} \mathrm{P}<0.05$, ${ }^{\star *} \mathrm{P}<0.01$, ${ }^{\star \star *} \mathrm{P}<0.001$. 